\title{
O MENOR PREÇO vs. O MELHOR PREÇO NAS LICITAÇÕES ${ }^{1}$
}

\author{
Carlos Alberto Day Stoever ${ }^{2}$ \\ Maicon Rodrigo Moreira Zambarda ${ }^{3}$
}

\begin{abstract}
RESUMO
O presente trabalho busca estabelecer um comparativo crítico entre a licitação pelo tipo menor preço e a maior vantagem tencionada pela Lei $\mathrm{n}^{\circ}$. 8.666/93, tratada aqui como o melhor preço. Numa exegese legal, pretende-se demonstrar que a visão de busca estrita pelo menor preço tem obtido indesejados resultados práticos, incompatíveis com a eficiência pretendia pela Administração Pública, onerando o erário com passivos trabalhistas, ficais e previdenciários que encarecem o custo real da contratação. Acredita-se, porém, ser tal quadro reversível em futuros certames se alterado o foco pretendido, levando-se em consideração a qualidade e a segurança jurídica da contratação.
\end{abstract}

PALAVRAS-CHAVE: Licitação, Menor Preço, Melhor Preço.

\begin{abstract}
This paper aims to establish a critical comparative between the bid at auction by the lower price and the biggest advantage intended for the Statute $\mathrm{n}^{\circ}$. 8.666/93, treated here as the best price. In a legal study, searchs to demonstrate that the vision of strict search for the lower price has gotten ackwards results, incompatible with the efficiency intended by the Public Administration, burdening the state treasury with working liabilities, that makes the real cost of the act of contract more expensive. It is given credit, however, such scenery to be reversible in future bids at auction if modified the intended focus, taking in consideration the quality and the legal security of the act of contract.
\end{abstract}

KEY-WORDS: Bid At Auction, Lower Price, Best Price.

\section{INTRODUÇÃO}

Dividindo-se as licitações entre os tipos menor preço, melhor técnica e técnica e preço, consoante o art. 45, $\S 1^{\circ}$ da Lei $n^{\circ}$. 8.666/93, cumpre, inicialmente, salientar ocorrer a maioria delas pelo menor preço, refletindo a incessante busca por redução das despesas da Administração Pública.

Nesse tipo, apesar de precipuamente importar somente o menor valor proposto, é exigida capacitação técnica para a habilitação dos licitantes, transmutando-se uma

\footnotetext{
${ }^{1} \mathrm{O}$ presente trabalho foi desenvolvido durante o período em que os autores trabalharam juntos no setor de licitações, enfrentando diariamente as dificuldades narradas, sendo concluído após o término do referido período, como parte da monografia de graduação do primeiro autor.

${ }^{2}$ Advogado Graduado em Direito pela UFSM. E-mail: carlos.stoever@jobimadvogados.com.br.

${ }^{3}$ Acadêmico do 4o Semestre do Curso de Direito da UFSM. E-mail: rodrigo@ sulclean.com.
}

ISSN - 1981-3694

(c) 2007. Departamento de Direito da UFSM. Todos os direitos reservados. 
imagem de garantia mínima de qualidade, que nem sempre ocorre em razão da necessária escolha do menor preço.

O acompanhamento diário de certames licitatórios e posterior execução dos contratos firmados demonstra que a busca incondicional pelo menor preço foi alavancada à pedra mestra de toda aquisição do Poder Público, sendo a tendência adotada no desenvolvimento de novas modalidades licitatórias (p. ex., pregão eletrônico e presencial) que buscam, em primeiríssimo lugar, o menor valor, para, depois, em caráter secundário, os demais aspectos circunscritos ao objeto.

Por certo, não há como se contemplar uma evolução administrativista sem modernizar o sistema licitatório, porém, isso não implica necessariamente em uma renovação da legislação - como tem se pregado no Congresso $\mathrm{Nacional}^{4}$-, mas uma correta interpretação da Lei $n^{\circ}$. 8.666/93, cuja principiologia é das mais avançadas na área das compras governamentais.

Há, primordialmente, um lapso na hermenêutica entre as pretensões da legislação e a correta visão das modalidades, não havendo que se falar simplesmente em menor preço absoluto, mas, sim em preço mais vantajoso para a Administração Pública, ponderando-se até que ponto o menor preço proporcionará efetivamente o menor custo ao erário.

E este amadurecimento dos procedimentos licitatórios ancora-se à eficiência administrativa tida por pressuposto básico da moderna concepção de administração gerencial, que atue com as características do mercado privado em busca de contratações vantajosas para si e, conseqüentemente, para a sociedade que a sustenta.

Tem-se por maior reflexo da eficiência nos contratos administrativos a busca pela maior vantagem possível para a Administração Pública, seja tal vantagem de cunho técnico, seja de cunho econômico.

Eis o objetivo do presente trabalho: avaliar doutrinária e casuisticamente qual o ponto de equilíbrio em que o menor preço deixa de ser o melhor preço para transformarse em uma situação falaciosa, proporcionando um baixíssimo valor, escondendo um enorme passivo em razão da igualmente baixa qualidade/eficiência do objeto contratado.

\section{DA HERMENÊUTICA DOS ARTS. $3^{\circ}$ e 45 DA LEI No $8.666 / 93$}

\footnotetext{
${ }^{4}$ Projeto de Lei ${ }^{\circ} .7 .709 / 2007$.
} 
Todo o sistema licitatório tem por cerne a principiologia trazida ao art. $3^{\circ}$ da Lei $\mathrm{n}^{\circ} .8 \cdot 666 / 93^{5}$, lá se encontrando os alicerces do que os operadores públicos devem buscar a cada contratação.

Tem-se elencado com clareza ser o objetivo de todo procedimento licitatório $a$ seleção da proposta mais vantajosa para a Administração. Em qualquer tipo pelo qual se pretenda contratar, o que se busca não é o simples fator preço, mas, também, a análise dos encargos que traz consigo.

De início, cumpre-se esclarecer o que é vantagem para Administração Pública. Com precisão, é possível apontar ser a proposta que proporciona uma contrapartida satisfatória, seja em termos de tecnologia, de qualificação de mão de obra, de qualidade nos materiais empregados, de segurança jurídica para futuras responsabilizações que recaiam sobre o erário, aliado ao menor custo possível.

Sabe-se que quando se quer adquirir um computador, basta estabelecer sua configuração que se alcançará, pelo menor valor, o bem pretendido. Porém, o mesmo não se pode dizer quando se pretende construir um prédio, no qual a qualidade do material implica em sua durabilidade e na segurança dos próprios servidores que nele irão laborar, além de estarem embutidos ao preço uma série de encargos trabalhistas, previdenciários e fiscais que recaem, subsidiariamente, sobre o ente contratante.

Muitos são os casos em que a empreiteira ganha a licitação, constrói o prédio e desaparece, deixando uma obra em condições precárias, com sérios riscos de ter a Administração Pública que arcar com os encargos não quitados e, ainda pior, ter de realizar nova licitação para atingir o mesmo objetivo.

Isso se defronta por haver uma inversão de valores nos procedimentos, sendo o menor preço o primeiro fator a ser considerado, e não mais um fator - de sensível importância - a ser composto ao lado de uma série de outros de grande relevância.

São mazelas colhidas por não haver uma apreciação correta da sistemática trazida à Lei de Licitações e Contratos Administrativos, olvidando-se do corolário básico do art. $3^{\circ}$ e concedendo maior importância para o julgamento trazido ao art. 45

\footnotetext{
${ }^{5}$ Lei no ${ }^{\circ} .8666 / 93$ - Art. $3^{\circ}$. A licitação destina-se a garantir a observância do princípio constitucional da isonomia e a selecionar a proposta mais vantajosa para a Administração e será processada e julgada em estrita conformidade com os princípios básicos da legalidade, da impessoalidade, da moralidade, da igualdade, da publicidade, da probidade administrativa, da vinculação ao instrumento convocatório, do julgamento objetivo e dos que lhes são correlatos.
} 
$\S 1^{\circ}$ inc. $I^{6}$, que refere ser a proposta mais vantajosa unicamente aquela que trouxer, para o que for especificado ao edital, o menor preço.

Esbarra-se, aqui, em problema ainda mais antigo: a elaboração de editais, que normalmente descrevem o objeto sem levar em conta pormenores e riscos que estão escondidos no bem/serviço a ser contratado, somente passíveis de previsibilidade por técnicos e que, se não forem considerados, causam graves lesões ao erário.

A simples leitura do texto legal demonstra que o tipo menor preço foi criado para situações em que a única problemática do objeto a ser contratado fosse efetivamente o preço, não sendo necessárias outras considerações - por haver uniformidade de mercado, com qualidade mínima satisfatoriamente estabelecida, a ponto de não se sobressair ante o valor da proposta.

Conforme ensina Marçal Justen Filho (2004), a necessidade de análise em variáveis de técnica ou qualidade foge da simplicidade pretendida pelo menor preço, complicando a análise das propostas e impondo óbices a todo o procedimento.

Ao próprio instrumento convocatório, deve-se atentar para não valorar possíveis benefícios propiciados pelos fornecedores, que podem tornar uma proposta mais interessante, apesar de não ser a de menor contraprestação pecuniária.

Entende-se a objetividade do julgamento, porém alguns produtos, ao não se enquadrarem nos tipos de técnica e técnica e preço, acabam sendo jogados ao rol do menor preço, cerceando uma contratação mais benéfica, na qual o bem/serviço seja fornecido/executado com maior qualidade ou menor risco ao erário, gerando uma equação custo/benefício que torna viável sua contratação - ainda que não possua o menor valor.

Acredita-se que o conceito ora utilizado para menor preço impede, em muitas oportunidades, que a Administração Pública celebre bons contratos, uma vez adstrita à menor proposta oferecida. Deve-se, sim, efetuar uma transição para que a análise passe

\footnotetext{
${ }^{6}$ Lei no ${ }^{\circ} .8 .666 / 93$ - Art. 45. O julgamento das propostas será objetivo, devendo a Comissão de licitação ou o responsável pelo convite realizá-lo em conformidade com os tipos de licitação, os critérios previamente estabelecidos no ato convocatório e de acordo com os fatores exclusivamente nele referidos, de maneira a possibilitar sua aferição pelos licitantes e pelos órgãos de controle.

$\S 1$ o Para os efeitos deste artigo, constituem tipos de licitação, exceto na modalidade concurso:

I - a de menor preço - quando o critério de seleção da proposta mais vantajosa para a Administração determinar que será vencedor o licitante que apresentar a proposta de acordo com as especificações do edital ou convite e ofertar o menor preço;

II - a de melhor técnica;

III - a de técnica e preço.

IV - a de maior lance ou oferta - nos casos de alienação de bens ou concessão de direito real de uso.
} 
a ser da proposta mais vantajosa, do melhor preço, mantendo-se a objetividade da licitação.

Isto é possível se forem conhecidos os fatores que podem influir na relação custo/benefício, tendo no preço seu fator primordial, porém não único, como hoje ocorre.

Trata-se, assim, de ponderar qual o interesse público que está em jogo, se este pode ser atendido pelo produto mais barato, ou se, de alguma outra forma, poderão específicas vantagens justificar a não contratação da menor proposta.

Devem, assim, serem avaliados também fatores como segurança, qualidade, capacidade técnica, fazendo com que se chegue a um denominador indicativo do melhor preço.

E não é só isso, na avaliação das propostas, devem-se levar em consideração diversos elementos que se agregam ao preço real do objeto, tais como tributos, prazos para pagamento, descontos, encargos trabalhistas, etc.

Tem-se, assim, um conglomerado de fatores que, sem dúvida, são capazes de tornar inviável o valor mais baixo e munir de atrativos outras propostas, cujo rol acaba não só justificando a elevação do preço, mas o tornando relativamente mais barato em uma visão ampla.

A interpretação legal correta gera contratações responsáveis, que, por sua vez, implicam em vantagens a médio e longo prazo para a Administração Pública, afastando - ou diminuindo sensivelmente - as chances de padecer com produtos de baixa qualidade e contratações precárias que, num curto espaço de tempo, oneram o erário com novas licitações do mesmo objeto, implementadas pelo simples insucesso das anteriores.

A eleição do melhor preço acarreta serviços duráveis, salvando os cofres públicos de contratações emergenciais ou repetidas, bem como da insegurança de haver inclusões orçamentárias por condenações subsidiárias, desestabilizando qualquer planejamento onde os maiores beneficiários seriam os administrados, por usufruírem de uma Administração Pública servidora, atingindo os objetivos por todos almejados.

Tal lição, aliás, já fora defendida por Hely Lopes Meirelles (2001), que a tinha como intrínseca ao próprio conceito de licitação, tratando como fração conceitual indissociável, sob pena de se perder a própria essência do instituto.

Assim, pretende-se estabelecer uma principiologia que confira certa liberalidade na avaliação das propostas, o que não significa trazer subjetividade ao certame, mas, 
sim, munir de mecanismos para atingir-se a melhor contratação, sendo este o objetivo maior da licitação, e não a simples contratação de um bem/serviço.

\section{DA AVALIAÇÃO DAS PROPOSTAS SOB A RELAÇÃO CUSTO/BENEFÍCIO}

Analisando a letra da lei e a hermenêutica pretendida à consolidada doutrina, tem-se que o objetivo da licitação encontrar a proposta mais vantajosa para o Poder Público, cabendo, então, verificar qual a relação custo/benefício que se pretende.

Nesse ínterim, tem-se que a falha está na aplicação do dispositivo legal, e não em sua parte textual; e é neste ponto que o ato convocatório e/ou o projeto básico tem seu papel fundamental, pois, se elaborados em estrito cumprimento da lei, em sincronia com a plena definição das necessidades e peculiaridades do objeto licitado, evitará que licitantes não qualificados apresentem propostas mal elaboradas - e, por óbvio, com os preços mais baixos.

Como citado anteriormente, falta a visão do procedimento licitatório como um todo, desde sua solicitação até a duração completa do contrato, e ainda muito pior, falta qualificação e entendimento do que realmente se quer quando a Administração Pública resolve contratar.

Para assegurar a realização de uma contratação segura e eficiente, é necessário que os editais contemplem todos os requisitos de qualidade acima mencionados, exigindo criteriosos quesitos para habilitação técnica/financeira, fazendo-os compor a escolha ao lado do quesito econômico.

Certo é que, dentro deste panóptico, tem-se ainda a escolha pelo menor preço, porém como critério subsidiário ao atendimento dos demais critérios, ainda quando seja simples o objeto, uma vez que raros são os certames em que não participem empresas interessadas em escoar seus produtos recusados pelo mercado privado ou em ter nos contratos públicos a chance de um lucro fácil, posto à ausência de fiscalização ou pela facilidade em ludibriá-la.

Ademais, a visão que se espera é aquela que contemple a pretensão imediata, mas com garantias de execução satisfatória, ou seja, contratar com quem tenha condições de cumprir rigorosamente o objeto licitado, e, tão importante quanto, com suas obrigações e encargos secundários, sejam eles fiscais, comerciais ou trabalhistas.

Uma má contratação torna a possível contratação ao menor custo bem mais cara do que se possa imaginar. Não há como não relacionar esta visão com políticas 
imediatistas, promotoras de uma distorcida idéia de economia, às custas de má qualidade dos bens/serviços contratados.

Com isso, remete-se à casuística: em meados de outubro de $2005^{7}$, o Hospital Universitário de Santa Maria, ao tolerar a participação de uma cooperativa em uma licitação para mão de obra, a escolheu por ser o menor preço proposto. Uma vez assinado o contrato, a licitante vencedora não tinha condições técnicas de assumir o contrato, tendo o ente público de socorrer-se em um contrato emergencial - com custo mais elevado - até a realização de um novo certame.

Neste caso, a cooperativa apresentava o valor mais baixo, cumprindo todos os demais requisitos, porém não apresentava, em sua composição de custos, fatores de segurança que a habilitassem a administrar o contrato.

Tivessem sido ponderados outros fatores, chegar-se-ia a conclusão de que alguns dentre os demais concorrentes poderiam proporcionar à instituição uma contratação mais segura, afastando contratempos que, se fossem admitidos, afastariam a necessidade de serem contratados terceiros ${ }^{8}$.

Na prática, são bastante comuns as situações em que o objeto é adjudicado ao licitante que oferece a menor proposta, mas que, meses depois, acaba por rescindir o contrato por incapacidade econômica de cumpri-lo, deixando para a Administração Pública um sensível passivo a ser honrado, seja com fornecedores, seja com empregados, obrigando-a, ainda, a realizar novo certame.

Tratando-se de passivo acumulado pelo erário, despiciendo comentários maiores do que o exemplo da Caixa Econômica Federal, que, em todos estes anos de licitações de mão de obra pelo menor preço, entre a quebra de algumas empresas e a inadimplência de outras, acumulou um passivo trabalhista que já ultrapassa a casa dos R\$ 700 milhões ${ }^{9}$.

\footnotetext{
${ }^{7}$ Edital Pregão Presencial nº. 66/2005 - Hospital Universitário de Santa Maria (HUSM).

${ }^{8}$ Quando a Administração Pública pretende contratar uma empresa para a realização de serviços auxiliares, que não constituem o fim do próprio órgão licitador, diz-se que está ocorrendo a terceirização do serviço.Isto implica em repassar as atividades de caráter meramente acessório, inseridas como atividades-meio, permitindo ao contratante concentrar-se nas atividades diretamente relacionadas ao seu próprio negócio, visando alcançar maior qualidade, produtividade e redução de custos.

9 BRASIL. Tribunal de Contas da União. Plenário. Auditoria de natureza operacional. Política de terceirização de serviços da Caixa. Avaliação da relação custo/benefício. Adequação às diretrizes e metas da empresa. Recomendações e determinações. Ciência ao Ministério Público do Trabalho. Monitoramento. Relator: Marcos Vinícius Vilaça. Acórdão nº 2.085 de 09 de dez. 2005. Disponível em: <http://www.tcu.gov.br>. Acesso em 12 out. 2006.
} 
Em contraponto, têm-se empresas como a Petrobrás, nas quais são constantes as pré-qualificações e análises aprofundadas das propostas de cada licitante, em busca da manutenção da qualidade que já possuem em seus respectivos ramos de atuação.

Quando o estabelecimento da qualidade almejada em cada área é consabido e conscientizado em cada servidor, a busca pela constante melhoria reflete em procedimentos licitatórios igualmente qualificados, com menores chances de más contratações por procurar-se não meros fornecedores, mas parceiros em qualidade.

Diante de exemplos como esses, fica evidente essa falsa economia, e é por isso que se apresentam essas reflexões sobre a busca indiscriminada pelo menor preço, cujas mazelas são terríveis se não levados em consideração o tipo de bem/serviço pretendido e a preparação adequada de seu ato convocatório e/ou projeto básico.

Há fortes tendências para que este quadro mude a partir do momento em que se encare a Administração Pública como um ente servidor, disposto a utilizar seus recursos para melhor servir à população, e isso terá um importante significado: aumento na qualidade, seja nos serviços prestados, seja nas contratações que se realiza.

Para evitar contratações equivocadas, absurdamente mais caras ao erário - seja pela repetição da licitação, seja pela má qualidade dos produtos -, há a necessidade de estabelecer-se maior segurança ao certame, licitando não o mínimo existente ao mercado, mas a melhor equação custo/benefício para o contratante, que atenda aos anseios de contenção de despesas sem ignorar os riscos e sacrifícios que compõem um preço demasiado baixo.

Bem alerta Marçal Justen Filho (2004) que o menor preço não envolve apenas uma consideração de valores absolutos, mas, sim, a razão de avaliação dos valores globais que a Administração Pública desembolsará para fruição do objeto licitado.

Sem embargo, não há defeito em se examinar questões técnicas para definir o melhor preço; justo o contrário, somente assim será possível examinar o rendimento e a apuração das qualidades propostas, definindo o melhor preço sem por em risco todo o certame.

Há de se ter em mente que o mercado privado não é isonômico, havendo, na maioria dos produtos, padrões de qualidade mínimos não respeitados pela concorrência - cada vez mais vil - que busca na venda para a Administração Pública uma válvula de escape para seus insucessos no mercado privado.

\section{DA EFICIÊNICA NA ANÁLISE DO MELHOR PREÇO}


Todo o acima exposto preconiza um bom andamento dos contratos administrativos, equilibrando-se os custos e benefícios a serem proporcionados para a Administração Pública.

Tal visão alinhada-se ao princípio da eficiência administrativa, erguido a princípio geral da Administração Pública com o advento da Emenda Constitucional n ${ }^{\circ}$. 19/98, estando hoje elencado ao caput do art. 37 da Constituição Federal ${ }^{10}$.

De complexa definição, tal princípio exsurge com clareza nas visões de Celso Antonio Bandeira de Mello (2005), que o remonta ao princípio italiano da boa administração, e de Paulo Modesto (2005), que traça um paralelo com o princípio da eficácia, da racionalização administrativa, da não burocratização e da economicidade que compõem a imposição ao Poder Público de administrar com retidão suas finanças, aplicando-as de modo salutar à sociedade, com presteza e qualidade.

Em nosso ordenamento, desde há muito se fala em eficiência administrativa, podendo ser considerado como marco inicial sua referência como finalidade da Administração Indireta, instituída pelo art. 26, inciso III do Decreto n ${ }^{\circ}$. 200/67 ${ }^{11}$. De igual modo, sempre obteve amparo à jurisprudência, que o abrigou em diversas decisões ${ }^{12}$ como princípio e dever da Administração Pública e seus agentes.

Nas contratações públicas, a eficiência apresentar-se ainda mais presente, uma vez ser pressuposto para uma boa aquisição, que atenda às pretensões de qualidade, segurança e economia - base tripla da excelência em contratos administrativos.

Com efeito, é um ditame pluridimensional, na acepção aderida por Paulo Modesto (2005), que aduz não poder ser entendido somente como economicidade na gestão dos recursos públicos, mas, também, como um equilíbrio entre os custos dos procedimentos e seu benefício final.

\footnotetext{
${ }^{10}$ Art. 37. A administração pública direta e indireta de qualquer dos Poderes da União, dos Estados, do Distrito Federal e dos Municípios obedecerá aos princípios de legalidade, impessoalidade, moralidade, publicidade e eficiência e, também, ao seguinte:

11 Art. 26. No que se refere à Administração Indireta, a supervisão ministerial visará a assegurar, essencialmente:

...

III - A eficiência administrativa.

12 A respeito, ver STF, RMS-2201/DF, Relator Ministro Abner Vasconcelos, publicado no DJ em 22/07/54. Julgamento em 07/01/1954 - Tribunal Pleno; STJ, RESP 169876/SP (98/0023955-3), publicado no DJ em 21/09/1998, p. 70 Relator Ministro José Delgado, Julgamento em 16/06/1998, Órgão Julgador T1 - PRIMEIRA TURMA; e STJ, ROMS 5590/DF (95/0016776-0) publicado no DJ em 10/06/1996, p. 20395 Relator Ministro Luiz Vicente Cernicchiaro, Julgamento em 16/04/1996 Órgão Julgador - Sexta Turma.
} 
Segue referindo que é necessário estar sob a égide da eficiência a escolha das ações e procedimentos adotados na busca de determinado objetivo da Administração Pública, impondo duas dimensões bem definidas: (a) racionalização e otimização dos meios e (b) satisfação das necessidades.

Indo-se além da faceta da economicidade, o princípio da eficiência apresenta nítida aproximação ao princípio da proporcionalidade, devendo ser adequados os meios aos fins, objetivando os melhores resultados, impelidos de qualidade e segurança.

A eficiência pode ser concebida como a excelência no desempenho das atividades, satisfazendo aos interesses internos e aos de seus consumidores, oferecendo produtos/serviços com qualidade.

E tal qualidade não encontra melhor definição senão a concedida pela própria Secretaria Geral da Presidência ${ }^{13}$ :

qualidade de serviço público é, antes de tudo, qualidade de um serviço, sem distinção se prestado por instituição de caráter público ou privado; busca-se a otimização dos resultados pela aplicação de certa quantidade de recursos $e$ esforços, incluída, no resultado a ser otimizado, primordialmente, a satisfação proporcionada ao consumidor, cliente ou usuário. (MORAES, 2003, p.321).

No entanto, quando se fala em realizar aquisições ou em celebrar contratos, a melhor definição está na busca da qualidade. Neste sentido, Hely Lopes Meirelles (2003) trata a eficiência como um controle de qualidade, sendo desempenhado em três linhas distintas: administrativa, econômica e técnica.

Neste ínterim, concebe-se que a grande missão da eficiência é justamente alinhar aspectos da atividade administrativa que devem seguir ao norte comum, tendo-se em relevo o desempenho de uma determinada tarefa de modo rápido, preciso e útil à coletividade, construindo uma noção de qualidade administrativa.

A eficiência vai muito além da escolha do menor preço, pois muitas vezes este não necessariamente corresponderá à melhor proposta. Para evitar esbarrar na contratação de um licitante que, a despeito de possuir a menor oferta, não apresente os predicados necessários para o bom desempenho do contrato, é de primordial importância a elaboração de um edital que abarque todos os critérios essenciais para atingir a finalidade da contratação, bem como a escolha de uma modalidade licitatória adequada à complexidade exigida pelo objeto.

\footnotetext{
${ }^{13}$ Portaria $n^{\circ}$. 05, de 14-11-1991, do presidente do Comitê Nacional da Qualidade e Produtividade.
} 
Ao optar estritamente pelo menor preço, se está deixando de lado a eficiência para agir estritamente vinculado à redução de custos, o que de modo algum se enquadra nos objetivos da busca pela qualidade.

Certo que se deve ter cautela, sendo a qualidade composta de critérios objetivos - dentre eles o preço - que conjuntamente permitam a escolha da melhor contratação pública, permitindo a longevidade de um contrato que atenda aos anseios do contratante.

Devido à grande diversidade de licitações realizadas pela Administração Pública - partindo desde a aquisição de material de escritório, até a execução da limpeza de um bloco cirúrgico -, Carlos Pinto Coelho Motta (1999) alerta para a necessidade de investir na qualificação dos servidores da comissão de licitações, conferindo capacitação para contratar todo tipo de bens e serviços, desprendendo igual rigor em todas as licitações, não permitindo que fiquem à mercê de especificações técnicas que desconhecem, podendo ser facilmente ludibriados pelos competidores.

Devem estar aptos a avaliarem uma proposta tendo-se em vista sua vantajosidade, e não simplesmente o menor preço. Em outra oportunidade, Carlos Pinto Coelho Motta (1999) salienta haver um descompasso na adstrição da escolha pelo menor preço, não correspondendo ao tão almejado eficiente atendimento das necessidades do interesse público.

O menor preço é, sem dúvidas, critério de seleção da proposta da melhor proposta, porém não reina absoluto, sendo integrante de uma equação de custo/benefício que atenda às expectativas da Administração Pública.

Deve-se, assim, analisar qual a proposta mais vantajosa - que ofereça o melhor preço - mantendo-se a objetividade da licitação. Isto é possível se conhecidos os fatores que podem influir na relação custo/benefício, tendo no preço seu fator primordial, porém não único a nortear a contratação.

Conforme entende Celso Ribeiro Bastos (2001), deve haver uma constante preocupação com o desempenho da Administração Pública, almejando-se os melhores resultados possíveis em suas atividades, como a celebração do melhor contrato possível, que atenda às especificações conjugadas com o menor dispêndio econômico.

E tais propósitos somente serão atingidos se bem definidos os objetivos de cada licitação: a celebração de um contrato com o fornecedor que o cumpra pelo menor valor possível; ou a contratação de ofereça a melhor equação custo/benefício, assimilando que a implementação de políticas de qualidade e eficiência possuem um custo superior à simples e direta execução contratual. 


\section{CONSIDERAÇÕES FINAIS}

Como visto, tornou-se objetivo principal contratar com custos reduzidos que, ao contrário do esperado, muitas vezes não é, e está longe de ser, a proposta mais vantajosa para o erário.

Deve-se buscar, assim, transpor o paradigma do menor preço, admitindo-se a Administração Pública como um ente servidor, focado na qualidade dos serviços que oferece e, por consequiência, do que consome, não significando um aumento de despesas, mas, sim, uma utilização racional e otimizada dos recursos que dispõe, dentro de uma harmônica equação custo/benefício.

Eis a interpretação pretendida dos artigos arts. $3^{\circ}$ e 45 da Lei $n^{\circ}$. 8.666/93: escolher proposta que atenda às necessidades do contratante, levando-se em conta fatores de eficiência, qualidade e segurança jurídica pelo menor preço possível, sem que este se sobreponha de modo absoluto àqueles.

Uma contratação em tais termos não só respeita a pretensão de redução de custos como atende à eficiência pretendida pela Administração Pública no desempenho de suas atribuições, contratando bens e serviços que proporcionem uma real vantagem por seus atributos, não se resumindo a eleger o menor valor, numa busca imediata que somente esconde futuros prejuízos.

Trata-se de focar o interesse público na qualidade, entendida esta como um conjunto de requisitos técnicos - dentre eles o preço - hábeis a possibilitar a melhor contratação, apurando-se na licitação o menor preço real, representante do menor desembolso para a Administração Pública, sendo este o real significado que se extrai da leitura da Lei de Licitações e Contratos Públicos para o conceito menor preço.

\section{REFERÊNCIAS BIBLIOGRÁFICAS}

BANDEIRA DE MELLO, Celso Antonio. Curso de Direito Administrativo. $19^{\mathrm{a}}$ ed. [S.1]: Malheiros, 2005.

BASTOS, Celso Ribeiro. Curso de Direito Administrativo. $5^{\text {a }}$ ed. Editora Saraiva, 2001.

BORGES, Alice Gonzalez. Inovações nas licitações e seus aspectos constitucionais. Revista Diálogo Jurídico, Salvador, CAJ - Centro de Atualização Jurídica, v. I, nº. 3, 
junho, 2001. Disponível em: <http://www.direitopublico.com.br>. Acesso em: 29 dez 2005.

BRASIL. Constituição da República Federativa do Brasil de 1988. 39ª ed. São Paulo: Saraiva, 2006.

BRASIL. Legislação Administrativa. 2a ed. São Paulo: Saraiva, 2006.

JUSTEN FILHO, Marçal. Comentários à Lei de Licitações e Contratos Administrativos. 10ª ed. São Paulo: Dialética, 2004.

MEIRELLES, Hely Lopes. Direito Administrativo Brasileiro. $26^{\text {a }}$ ed.São Paulo:Malheiros, 2001.

MEIRELLES, Hely Lopes. Direito Administrativo Brasileiro. $28^{\mathrm{a}}$ ed. São Paulo: Malheiros, 2003.

MODESTO, Paulo. Notas para um Debate sobre o Princípio Constitucional da Eficiência. Revista Diálogo Jurídico, Salvador, CAJ - Centro de Atualização Jurídica, v. I, $\mathrm{n}^{\circ}$. 2, maio, 2001. Disponível em: <http://www.direitopublico.com.br>. Acesso em: 29 dez de 2005.

MORAES, Alexandre de. Direito Constitucional. 14ª ed. São Paulo: Atlas, 2003.

MOTTA, Carlos Pinto Coelho. Impactos da Emenda Constitucional $\mathbf{n}^{\mathbf{0}} . \mathbf{1 9 / 9 8}$ e da Lei $\mathbf{n}^{\mathbf{0}}$. 9.648/98 na Lei de Licitações. Boletim de Licitações e Contratos, NDJ, nº 7 p. 438-445, 1999. 